\title{
Gravity variation around Shinmoe-dake volcano from February 2011 through March 2012-Results of continuous absolute gravity observation and repeated hybrid gravity measurements
}

\author{
Shuhei Okubo ${ }^{1}$, Yoshiyuki Tanaka ${ }^{1}$, Sadato Ueki $^{2}$, Hiromitsu Oshima ${ }^{3}$, Tokumitsu Maekawa ${ }^{3}$, and Yuichi Imanishi ${ }^{1}$ \\ ${ }^{1}$ Earthquake Research Institute, The University of Tokyo, Tokyo 113-0032, Japan \\ ${ }^{2}$ Graduate School of Science, Tohoku University, Sendai 980-8578, Japan \\ ${ }^{3}$ Graduate School of Science, Hokkaido University, Sapporo 060-0810, Japan
}

(Received October 27, 2012; Revised February 24, 2013; Accepted March 22, 2013; Online published July 8, 2013)

\begin{abstract}
We report here on continuous absolute gravity measurements made between February 2011 and March 2012 and repeated relative gravity measurements in the vicinity of Shinmoe-dake volcano, which commenced erupting in late January 2011. We find that 20 of 24 eruptive events are associated with precursory short-term gravity decreases occurring over 5-6 hours followed by quick recoveries lasting 1-2 hours. Also evident are significant long-term gravity changes arising principally from hydrological processes around the volcano, where annual precipitation exceeds $5,000 \mathrm{~mm}$. To isolate the gravity signal associated with volcanic processes, we compared gravity measurements made at 15 sites in March 2011 and again in March 2012. The gravity changes and crustal deformation observed during the one year period are well explained by $6 \times 10^{6} \mathrm{~m}^{3}$ inflation of a magma reservoir at a depth of $9 \mathrm{~km}$ and intrusion at shallower depths of a dike with dimensions of $10 \mathrm{~km} \times 0.5 \mathrm{~km} \times 0.5 \mathrm{~m}$.
\end{abstract}

Key words: Absolute gravity, precursory gravity signal, magma transport, Shinmoe-dake volcano.

\section{Introduction}

Eruptions of Mt. Shinmoe-dake, a member of the Kirishima volcano group, are documented to have occurred in 1716-1717, 1771, 1822, 1959, 1991, 2008, and 2010 before the most recent magmatic eruptions in January 2011. Subplinian eruptions on January 26 and 27, 2011 were followed by formation of a lava dome and frequent vulcanian eruptions in February 2011 (Nakada et al., 2013; Suzuki et al., 2013a, b). Although crustal deformation data revealed deflation of a magma source in the early stage of the eruption, subsequent observations until November 2011 suggested that magma accumulation was continuing (Nakao et al., 2011; Geospatial Information Authority of Japan et al., 2012).

We carried out two types of gravity observations from early February 2011 to investigate mass transport processes related to the volcanic activity. They are continuous absolute gravity measurements at a fixed station and repeated gravity observations at sites around the Kirishima volcanoes. These two types of measurement are complementary in the sense that the former has higher temporal resolution and poorer spatial resolution than the latter, and vice versa. This study presents the results of integrating the two types of observations to describe the overall picture of mass movement beneath the Kirishima volcanoes.

Copyright (C) The Society of Geomagnetism and Earth, Planetary and Space Sciences (SGEPSS); The Seismological Society of Japan; The Volcanological Society of Japan; The Geodetic Society of Japan; The Japanese Society for Planetary Sciences; TERRAPUB.

doi:10.5047/eps.2013.03.014

\section{Absolute Gravity Measurement}

\subsection{Instruments}

We used a free-fall type absolute gravimeter FG5 (Niebauer et al., 1995), in which the acceleration of a freefalling target is measured in a vacuum chamber with a laser interferometer and a rubidium atomic clock. We usually average a set of $N_{\text {drop }}=50$ measurements acquired within a prescribed time window of 500 seconds to obtain a single value $g_{\text {set }}$ representing that set. Successive time windows are separated by either 30 or 60 minutes (Table 1). The standard deviation of each measurement within a set is $\sigma_{\text {drop }} \approx 10-100 \mu$ gal $\left(1 \mu\right.$ gal $\left.=10^{-6} \mathrm{~cm} / \mathrm{sec}^{2}\right)$ depending on the level of ground noise. The precision of $g_{\text {set }}$ is thus estimated to be $\sigma_{\text {set }} \approx 1-15 \mu$ gal based on the relationship

$$
\sigma_{\text {set }}=\sigma_{\text {drop }} / \sqrt{N_{\text {drop }}}
$$

The overall accuracy of our measurements is evaluated to be better than 1-2 $\mu$ gal if data are averaged over one day or more to eliminate possible errors arising from ocean tide corrections (Okubo et al., 1997).

\subsection{Location of the absolute gravity station}

We installed the FG5 gravimeter at the Kirisima Volcano Observatory (KVO), $5.8 \mathrm{~km}$ northwest of Shinmoe-dake volcano (Table 2, Fig. 1). The horizontal distance $R$ between KVO and a magma chamber centered at a depth of $D=7 \mathrm{~km}$ inferred from the crustal deformation data is only $1 \mathrm{~km}$ (Nakao et al., 2011) (Fig. 1(b)). The change in the volume of this magma chamber during the 8 months preceding the subplinian eruptions is estimated to be $7.9 \times 10^{6}$ $\mathrm{m}^{3}$ (Imakiire and Oowaki, 2011), implying a mass increase of about $\Delta M \approx 2 \times 10^{10} \mathrm{~kg}$. Based on these estimates, we 
(a)

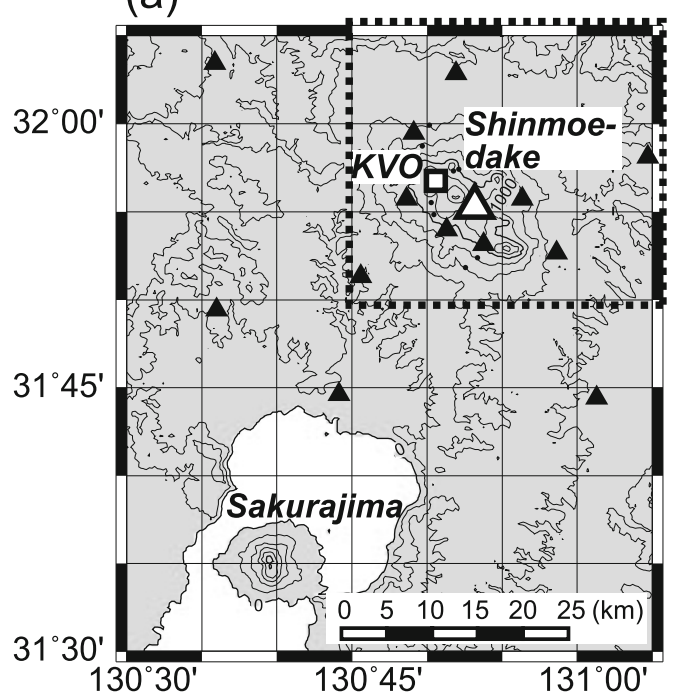

(b)

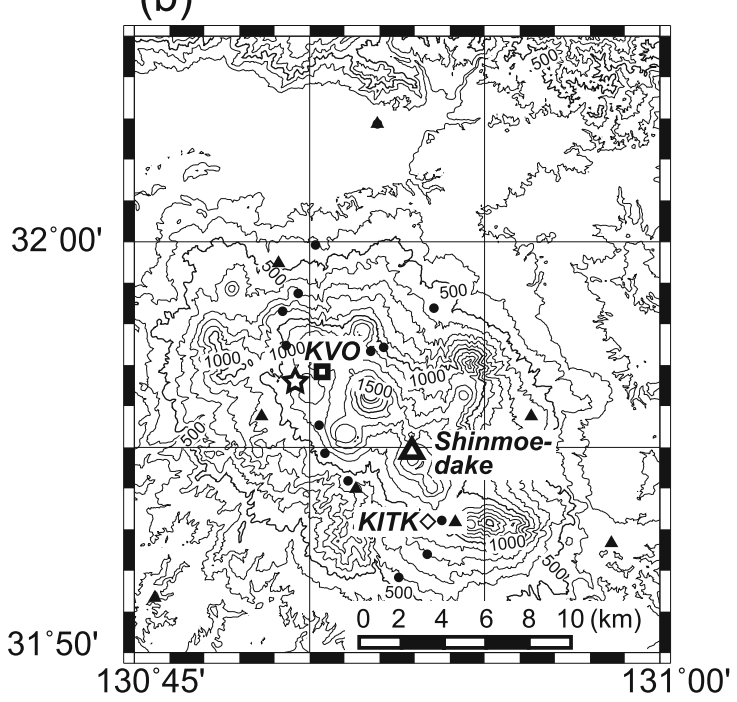

Fig. 1. Location of Shinmoe-dake volcano, and GPS, gravity, and ground tilt stations. (a) KVO stands for the absolute gravity station, Kirisima Volcano Observatory. GPS stations of the Geospatial Information Authority of Japan (GSI), the Japan Meteorological Agency (JMA) and the National Research Institute for Earth Science and Disaster Prevention (NIED) are denoted with solid triangles (Geospatial Information Authority of Japan et al., 2012). Contours are drawn every 200 meters above mean sea level. (b) Relative gravity points and a tilt station KITK operated by JMA are marked with solid circles and a diamond, respectively. The star symbol denotes an inferred inflation/deflation source at $7 \mathrm{~km}$ depth described by Nakao et al. (2011). Contours are drawn every 100 meters above mean sea level.

Table 1. Overview of absolute gravity measurements made between February 2011 and March 2012. Mean gravity values are computed for each set of 50 drops.

\begin{tabular}{ccc}
\hline Observation period & Set interval & Drops/set \\
\hline $2 / 8 / 2011-2 / 12 / 2011$ & $60 \mathrm{~min}$ & 50 \\
$2 / 12 / 2011-3 / 6 / 2011$ & $30 \mathrm{~min}$ & 50 \\
$3 / 6 / 2011-3 / 11 / 2011$ & (Instrumentation problems) \\
$3 / 11 / 2011-3 / 23 / 2011$ & (Operation halted due to \\
& the Tohoku Earthquake) \\
$3 / 24 / 2011-3 / 29 / 2011$ & 30 min & 50 \\
$3 / 30 / 2011-4 / 15 / 2011$ & 60 min & 50 \\
$4 / 16 / 2011-4 / 28 / 2011$ & (Instrumentation problems) \\
$4 / 29 / 2011-3 / 20 / 2012$ & 60 min & 50 \\
\hline
\end{tabular}

may say that direct attraction arising from the mass change

$$
\Delta g^{\text {mass }}=G \Delta M D /\left(R^{2}+D^{2}\right)^{3 / 2}=3 \mu \mathrm{gal},
$$

exceeds the observational errors of $\epsilon=1-2 \mu \mathrm{gal}$, where $G$ stands for the Newton constant.

\subsection{Short-term gravity signal}

2.3.1 Time series of absolute gravity at KVO Figure 2 shows the record of absolute gravity during the first 2 months of our experiment when Shinmoe-dake volcano was frequently repeating vulcanian eruptions (Nakada et al., 2013; Suzuki et al., 2013a). Unfortunately, the time series is interrupted in three places (Table 1). The first and the third breaks from March 6 until March 23, 2011 and from April 16 until April 28 were due to unanticipated problems with instrumentation, while the second break just after March 11, 2011 was imposed to avoid strong ground motions caused by aftershocks of the Tohoku earthquake (M 9.0). The data nevertheless provide us with invaluable information on the magmatic process within Shinmoe-dake volcano.
Table 2. Geographical coordinates of KVO (see also Fig. 1).

\begin{tabular}{cc}
\hline (Latitude, Longitude, Height) & $\begin{array}{c}\text { Distance to } \\
\text { Shinmoe-dake } \\
\left(31.9474^{\circ}, 130.8394^{\circ}, 1,200 \mathrm{~m}\right)\end{array}$ \\
\hline
\end{tabular}

We observe peculiar temporal changes before the eruptions denoted as VE\#1-VE\#3 and E\#4-E\#5 in Fig. 2. Gravity started decreasing $c a$. 7 hours before each eruption, and then increased rapidly over 1-2 hours immediately before the eruption (Fig. 2). It is true that similar gravity changes that are not accompanied by volcanic eruptions are discernible. However, they are generally associated with impulsive ground tilt variations exceeding a threshold value of 0.03 microradian (T\#1-T\#19 in Fig. 2). This threshold value is adopted on the basis that (1) ground noise levels are typically less than 0.03-0.05 microradian even on stormy days such as February 11-12, 2011, and that (2) tilt changes during the vulcanian eruptions $V E \# 1-3$ are $0.03,0.05$, and 0.10 microradian, respectively (Fig. 3).

Since both precursory and co-eruptive ground tilt changes are recorded in association with eruptions $V E \# 2$ and $V E \# 3$ (Fig. 3), tilt events $T \# 1-T \# 19$ are likely to represent either aborted or otherwise unobserved eruptions, that release overpressure from the crater without ejecting significant amount of materials (Japan Meteorological Agency et al., 2011; Kato and Yamasato, 2013). This interpretation is supported by the fact that event $T \# 9$, which occurred at midnight local time on February 22, 2011, is most likely an unobserved eruption since a small amount of fresh volcanic ash was identified on the morning of February 23, 2011 (personal communication from Dr. S. Nakada).

The data shown in Fig. 2 raise the possibility that eruption hysteresis after the end of March, 2011 could be exam- 

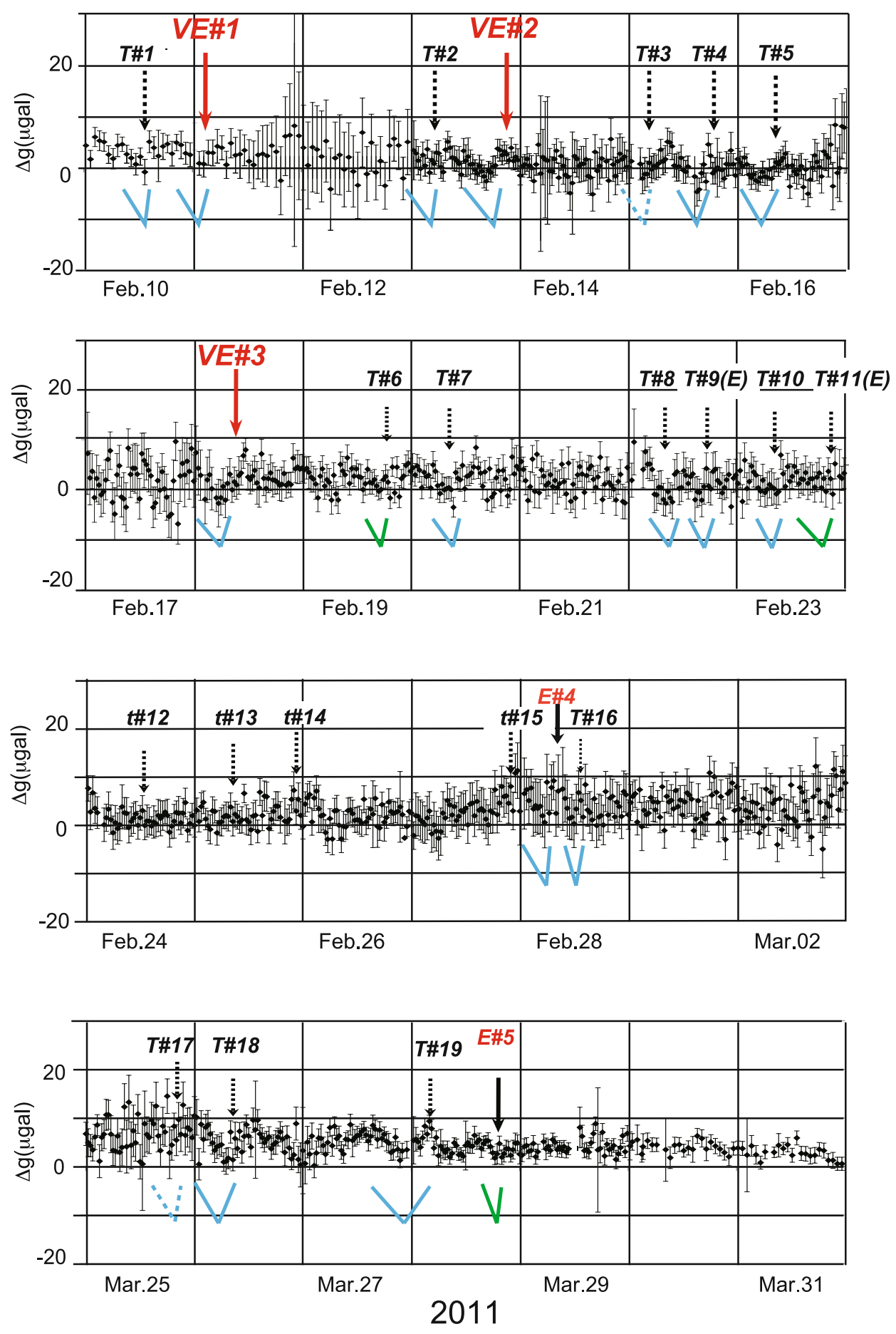

Fig. 2. Absolute gravity at the Kirisima Volcano Observatory (KVO in Fig. 1) as a function of Universal Time during the vulcanian eruption stage of Shinmoe-dake volcano in 2011. $\Delta g$ stands for gravity deviation from a nominal value of 979,222,030 $\mu$ gal. Approximately $90 \%$ of data in a set are within error bars as they represent $1.65 \times$ "standard deviation of gravity values in a set". Linear gravity decreases corresponding to the colored wedges are judged to be significant at either a $1 \%$ level (blue) or a $5 \%$ level (green), based on an $F$-test. The dotted wedges were identified by visual inspection but insufficient data are available to perform the $F$ test. VE\#1-VE\#3 stand for vulcanian eruptions, E\#4-E\#5 for small-scale eruptions, and $T \# 1-T \# 19$ for ground tilt events that are likely to represent aborted or overlooked eruptions. Four tilt events $t \# 12-t \# 15$ seem to occur without corresponding significant gravity changes.

ined. However, the coarser gravity measurement sampling after March 30, 2011 does not allow us to derive reliable correlations between tilt and gravity changes (Table 1).

2.3.2 Statistical test on the significance In this section, we demonstrate that our claims regarding the characteristic pattern of a short-term gravity decrease and a quick recovery are statistically justified. Gravity $g_{i}$ at a time $t=t_{i}$ can be modeled as a sum of a linear trend and normally distributed random noise $w_{i}$ with zero mean and unknown variance $\sigma^{2}$ as

$$
g_{i}=a+b t_{i}+w_{i} ; i=1,2, \ldots N
$$



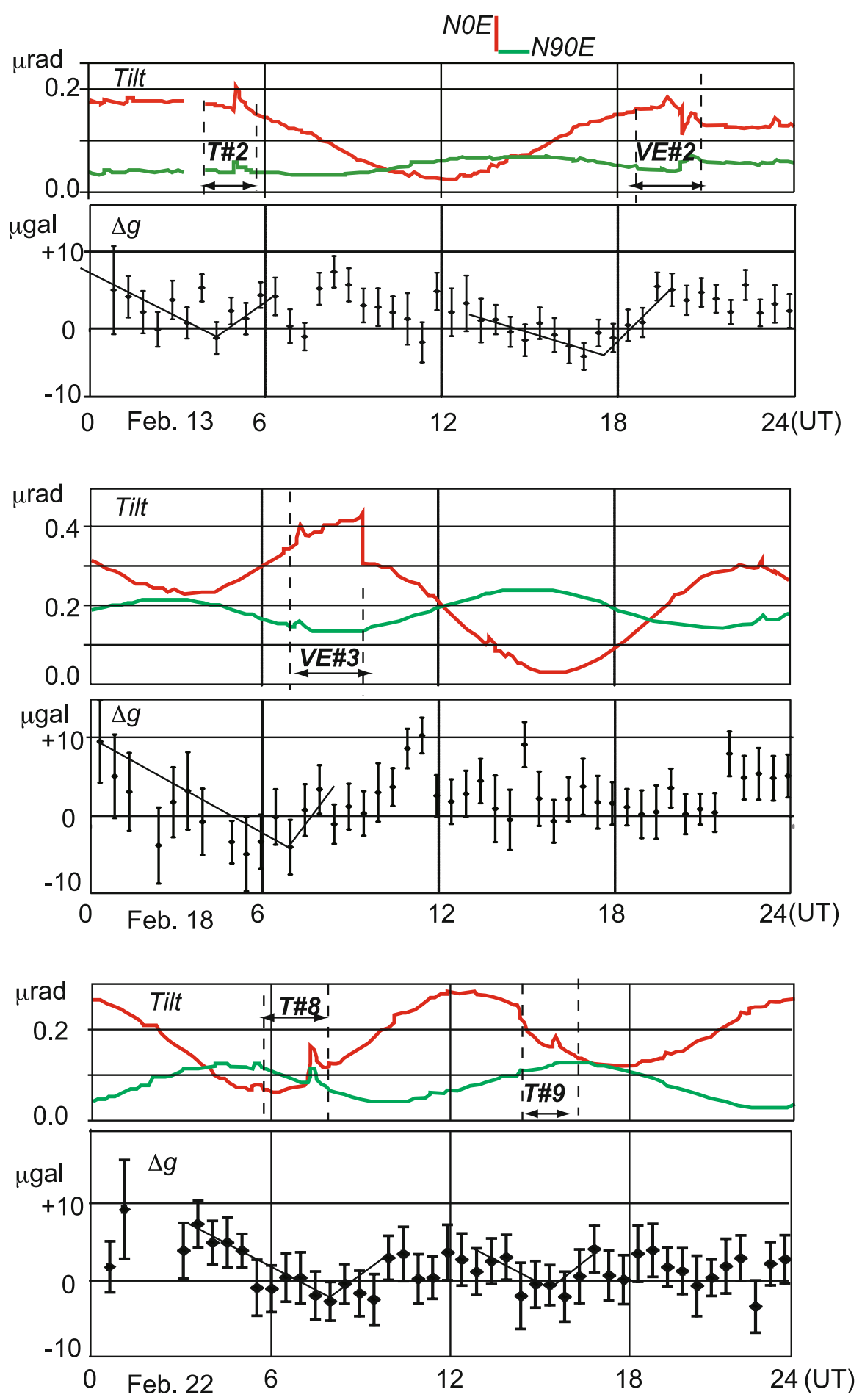

Fig. 3. Ground tilt at KITK in Fig. 1(b) and gravity change on February 13, February 18, and February 22, 2011. Both precursory and co-eruptive ground tilt changes are recorded in association with eruptions VE\#2 and VE\#3. The duration of each tilt event is 1-2 hours. Courtesy of the Japan Meteorological Agency.

The linear regression coefficients $a$ and $b$ can be found by minimizing

$$
\sum_{i=1}^{N}\left(g_{i}-a-b t_{i}\right)^{2}
$$

We may test the null hypothesis

$$
H_{0}: b=0
$$

using analysis of variance (ANOVA) (Davis, 1986). If the null hypothesis is correct, the $F$ value defined as

$$
\begin{aligned}
F & =S S_{R} /\left[S S_{D} /(N-2)\right], \\
S S_{R} & =\sum_{i=1}^{N}\left(a+b t_{i}-\bar{g}\right)^{2}, \\
S S_{D} & =\sum_{i=1}^{N}\left(a+b t_{i}-g_{i}\right)^{2},
\end{aligned}
$$


Table 3. F-test results for linear regression models applied to gravity changes before eruptions and impulsive tilt events in February and March 2011. $T \# 3$ and $T \# 17$ are not tested due to the limited number of data with suitably small errors.

\begin{tabular}{|c|c|c|c|c|c|}
\hline $\begin{array}{l}\text { Event ID } \\
\text { in Fig. } 2\end{array}$ & $\begin{array}{c}\text { Date and time } \\
\text { (UT) }\end{array}$ & $\begin{array}{l}\text { Number } \\
\text { of data } N\end{array}$ & $\begin{array}{l}\text { Gravity change } \\
\text { rate ( } \mu \text { gal/hour) }\end{array}$ & $F(1, N-2)$ & $\begin{array}{c}\text { Critical } F \text { for } \\
1 \% \text { confidence }(5 \%)\end{array}$ \\
\hline$T \# 1$ & 11:00-13:00, Feb. 11 & 5 & -1.04 & 86.8 & 34.1 \\
\hline$V E \# 1$ & 02:36, Feb. 11 & 5 & -0.83 & 95.0 & 34.1 \\
\hline$T \# 2$ & 05:00, Feb. 13 & 5 & -1.80 & 42.4 & 34.1 \\
\hline$V E \# 2$ & 20:07, Feb. 13 & 11 & -0.96 & 50.4 & 10.6 \\
\hline$T \# 3$ & 05:00, Feb. 15 & - & - & - & - \\
\hline$T \# 4$ & 19:00, Feb. 15 & 7 & -1.40 & 24.8 & 16.3 \\
\hline$T \# 5$ & 09:00, Feb. 16 & 10 & -1.05 & 35.4 & 11.3 \\
\hline$V E \# 3$ & 09:16, Feb. 18 & 9 & -1.66 & 16.7 & 12.2 \\
\hline$T \# 6$ & 18:30, Feb. 19 & 6 & -1.35 & 10.5 & $21.2(7.7)$ \\
\hline$T \# 7$ & 08:25, Feb. 20 & 10 & -1.24 & 15.0 & 11.3 \\
\hline$T \# 8$ & 07:45, Feb. 22 & 10 & -2.14 & 39.2 & 11.3 \\
\hline$T \# 9(\mathrm{E})$ & 15:00-16:00, Feb. 22 & 9 & -1.40 & 24.5 & 12.2 \\
\hline$T \# 10$ & 10:50, Feb. 23 & 13 & -0.68 & 15.5 & 9.6 \\
\hline$T \# 11$ & 14:00-18:37, Feb. 23 & 10 & -0.52 & 5.4 & $11.3(5.3)$ \\
\hline E\#4 & 08:00, Feb. 28 & 9 & -1.47 & 22.1 & 12.2 \\
\hline$T \# 16$ & 12:00, Feb. 28 & 7 & -2.25 & 39.2 & 16.3 \\
\hline$T \# 17$ & 20:30, Mar. 25 & - & - & - & - \\
\hline$T \# 18$ & 09:30, Mar. 26 & 11 & -1.21 & 21.1 & 10.6 \\
\hline$T \# 19$ & 04:30, Mar. 28 & 14 & -0.85 & 20.1 & 9.3 \\
\hline E\#5 & 18:33, Mar. 28 & 10 & -0.71 & 10.9 & $11.3(5.3)$ \\
\hline
\end{tabular}

(a)

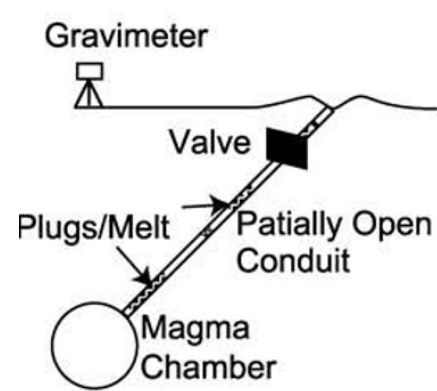

$\mathrm{T}<-7$ hours (b)

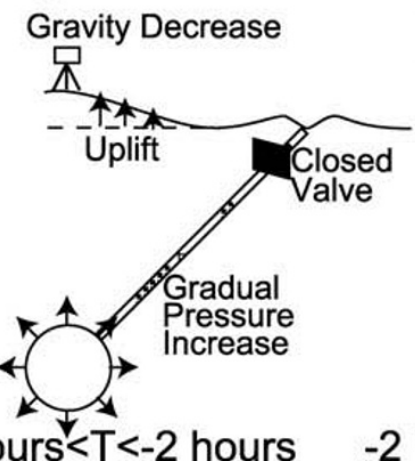

(c)

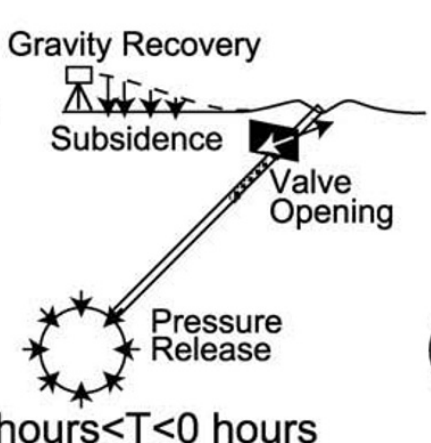

(d)

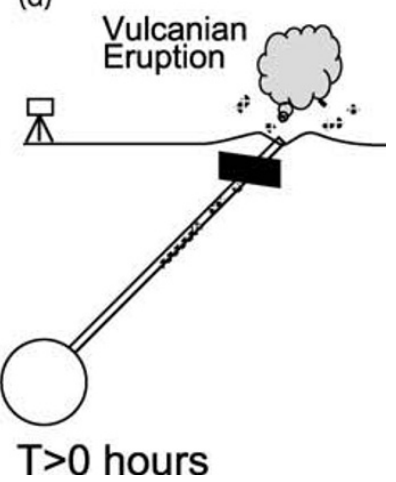

Fig. 4. Schematic model of the short-term gravity signal preceding vulcanian eruptions. (a) The conduit is choked with plugs. (b) As the pressure in the magma chamber increases, the surface above the chamber is uplifted, leading to a gravity decrease. (c) When the pressure is released by rupture in the shallow part of the conduit, the surface subsides causing an increase in gravity. (d) Within a short time, the pressure release leads to an eruption emitting choking materials out of the conduit.

$$
\bar{g}=\sum_{i=1}^{N} g_{i} / N
$$

is expected to be unity because it is a realization of a statistical variable drawn from the $F$ distribution with degrees of freedom 1 and $(N-2)$. If $b$ is not zero, $F$ becomes much larger than unity (Davis, 1986). We compute $F$ values for the linear regressions during the decreasing phases, for which sufficient data $(N=9-11)$ are available. On the other hand, we cannot perform the $F$ test for linear regression during the 2-hour increasing phases as too few measurements $(N=3-4)$ of data are available even in the case of 30-minute sampling (Table 1).

The $F$ values in Table 3 clearly show that the null hypothesis can be safely rejected at the $1 \%$ level of confidence in most cases. We thus conclude that each observed linear regression is very unlikely to have been produced by ran- dom fluctuation about a constant gravity value. Two points require further discussion, however. First, there are four exceptions, $t \# 12$ through $t \# 15$, for which the characteristic gravity changes are not visible. The reason for this is not clear, but the gravity decreases may have been smaller than the observational errors of a few microgal. Second, some additional V-shaped gravity changes occur, notably on the afternoon of February 18 and the morning of February 19 . The $F$-test shows, however, that these linear gravity decreases are not significant at the $1 \%$ confidence level, since the corresponding $F$-values of 3.2 and 6.1 do not exceed the critical values of 9.6 and 9.30 for $(1,11)$ and $(1,12)$ degrees of freedom, respectively.

2.3.3 Modeling the pre-eruption gravity change Figure 4 illustrates a conceptual model we propose in order to explain pre-eruption gravity decreases of $5 \mu$ gal. We assume a pressure source at some depth that represents 


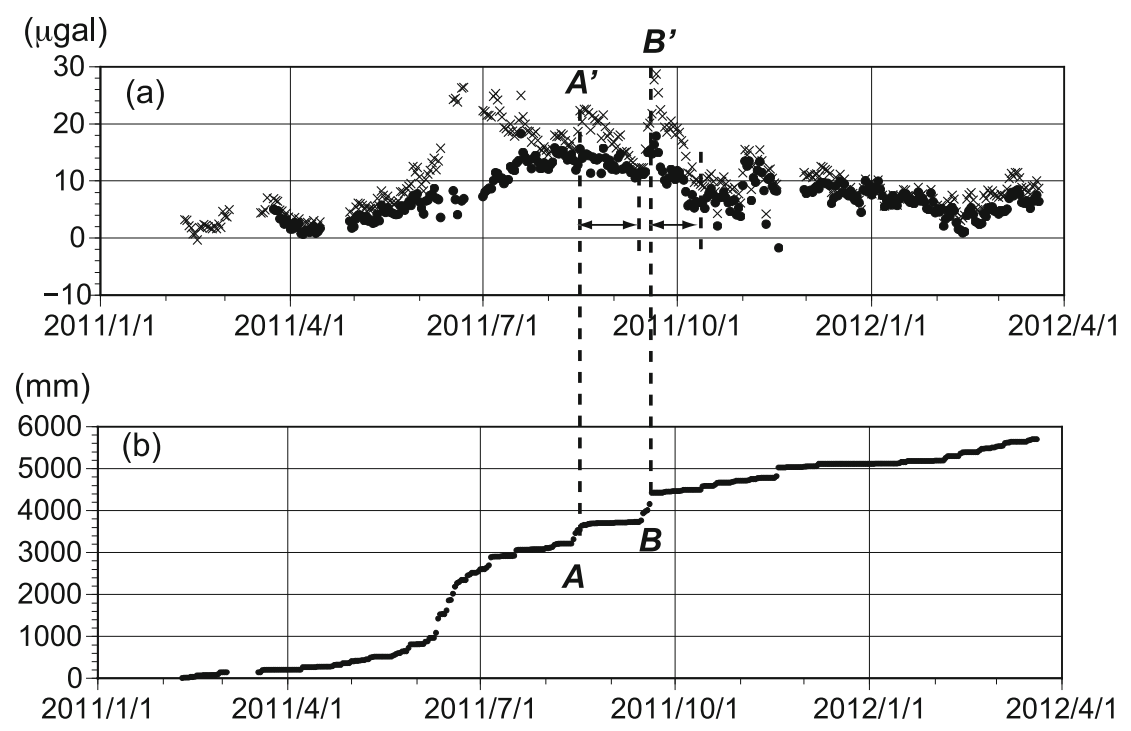

Fig. 5. Gravity disturbance arising from precipitation. (a) Absolute gravity minus a nominal value of 979,222,030 $\mu$ gal at the Kirisima Volcano Observatory (KVO in Fig. 1). The symbols $\times$ and $\bullet$ stand for gravity before and after correcting for the precipitation effect given by Eq. (10), respectively. (b) Cumulative precipitation between February 2011 and March 2012. Impulsive rainfall events are observed in mid-August (A) and in late September (B), causing systematic disturbance to the gravity data ( $A^{\prime}$ and $B^{\prime}$ in the upper panel). The horizontal arrows in the upper panel indicate that the relaxation time after impulsive rainfall is of order 30 days.
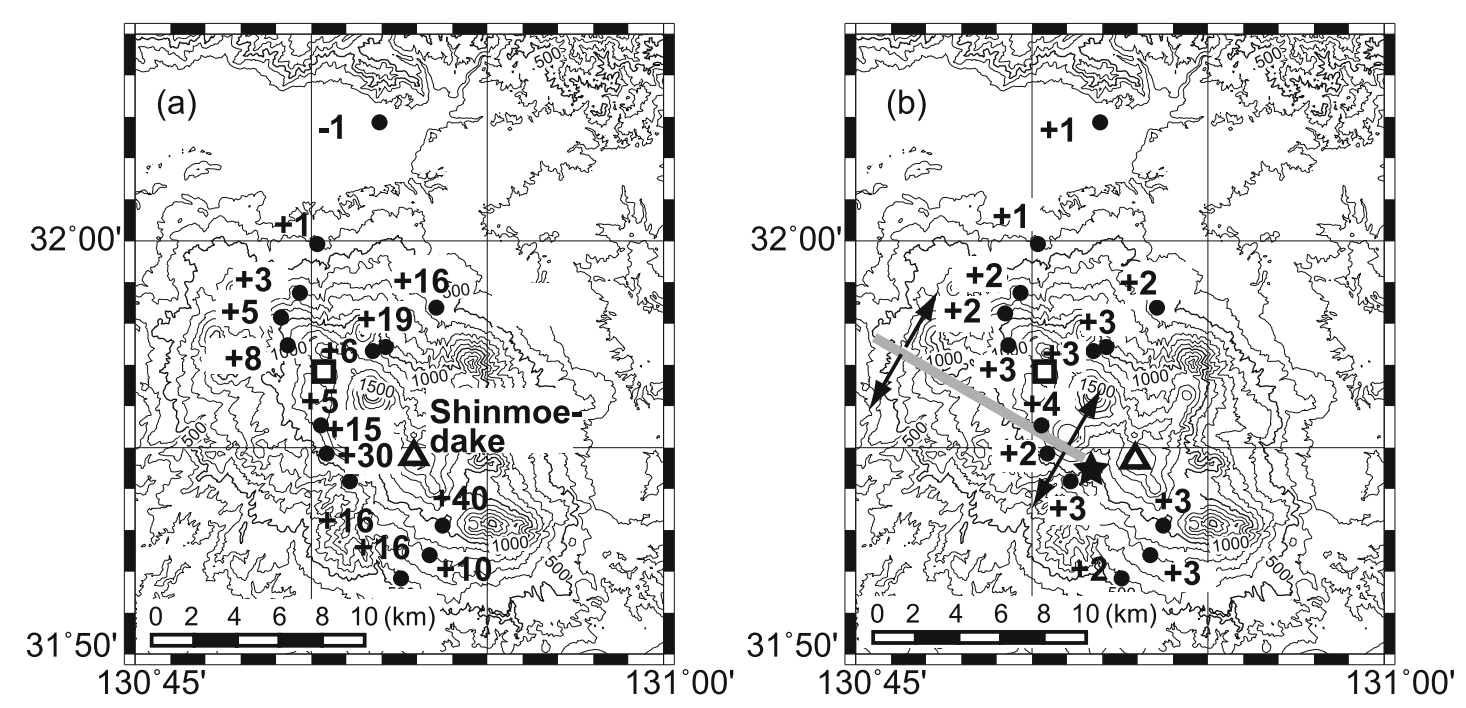

Fig. 6. Gravity changes in the year following the 2011 eruption. The units are $\mu$ gal. (a) Observed change from March 2011 to March 2012 . (b) Gravity change expected for the model shown in Fig. 7 and Table 4. The symbol star denotes an inflation/deflation source at $9 \mathrm{~km}$ depth while the shaded rectangle represents a shallower dike.

the magma reservoir of the 2011 Shinmoe-dake eruption (Nakao et al., 2011), and presume that the conduit leading to Shinmoe-dake volcano is partly choked with plugs. As the pressure in the magma reservoir increases, the surface above the chamber will undergo uplift, producing a gravity decrease (Hagiwara, 1977). When the pressure is released by either dike intrusion at a shallower depth or by an eruption ejecting the obstructing material from the summit crater, the surface subsides causing a gravity recovery. Since ground tilt is more sensitive to shallow sources than vertical displacement of the surface, changes in tilt are only expected, according to this model, in the later stages of the process (Fig. 4(c)). The expectation is consistent with the relationships illustrated in Fig. 3 in that most of the tilt events became evident only when has gravity begun to increase in response to the opening of a shallow valve (Fig. 4(c)).

Uplift of $w=20 \mathrm{~mm}$ at the gravity station is sufficient to cause a $5 \mu$ gal gravity change (Hagiwara, 1977) but too small to be detected with GPS. The horizontal displacement $(u, v)$ due to the pressure release will also be too small to detect with GPS because it is of the order of $(R / D w)=$ $(1 / 9) w \approx 2 \mathrm{~mm}$ where $R \approx 1 \mathrm{~km}$ denote the distance from the pressure source at a depth $D=9 \mathrm{~km}$ (cf. Eqs. (14)-(16), Fig. 6, and Table 4 below).

\subsection{Long-term gravity changes}

We next describe long-term gravity changes observed between February 2011 and March 2012. To increase the accuracy and precision of our analysis, we compute daily means of the gravity measurements, which are illustrated 
in Fig. 5(a). The error in the daily means is estimated to be $\sigma_{\text {drop }} / \sqrt{N_{\text {daily }}} \approx 0.3-3 \mu$ gal since we have $N_{\text {daily }}=$ $48 \times N_{\text {drop }}=1,200$ measurements a day and $\sigma_{\text {drop }}=10$ $100 \mu$ gal.

The 13 month record shows gravity variations of as much as $25 \mu \mathrm{gal}$ (Fig. 5(a)). The gravity changes cannot be ascribed solely to volcanic processes as gravity is also sensitive to variations in the water table and soil moisture (Torge, 1989). It is thus crucially important to eliminate hydrological disturbances from the observed gravity data set so that we may isolate the volcanic gravity signals of interest.

A sophisticated procedure for estimating hydrological effects on gravity when the hydrological structure around the gravity station is known was described by Kazama and Okubo (2009). As the hydrological structure around our station is not well known, we instead use an empirical tank model that assumes an instantaneous gravity response $\delta g(t)$ to rainfall $R(t)$ followed by gradual linear relaxation (Imanishi et al., 2006) according to

$$
\delta g(t)=C \sum_{i=0}^{J} a_{j} R(t-j \Delta t)
$$

where $\Delta t$ (=1 day) stands for the sampling interval, and $C$ and $a_{j}$ are the system response parameters of the tank model.

Gravity relaxation observed after points $A^{\prime}$ and $B^{\prime}$ in Fig. 5(a) indicates that the relaxation time $J \Delta t=30$ days and $a_{j}=[1-(j / J)]$. After trial and errors, we find $C=0.016 \mu \mathrm{gal} / \mathrm{mm}, 40 \%$ of the theoretical value of $0.042 \mu \mathrm{gal} / \mathrm{mm}$ for a flat distribution of groundwater (Torge, 1989), accounts for the transient gravity changes well. This value is reasonable since groundwater above the absolute gravimeter partly cancels out the attraction of water beneath it, and KVO is located on a hill slope of 15 degrees.

Once the data have been corrected for rainfall, few abrupt changes remain in the record of $\Delta g(t)=g(t)-\delta g(t)$ (Fig. 5). However, the long-term gravity changes $\Delta g(t)$ do still exhibit seasonal variations of $\pm 5 \mu$ gal (high in summer and low in winter), emphasizing the need to perform repeated relative gravity measurements in the same seasons to avoid hydrological effects.

\section{Repeated Hybrid Gravity Measurement 3.1 Instrument and setting}

Precise relative gravity measurements were made at 15 points around Shinmoe-dake volcano in March and August 2011 and in March 2012 using four LaCoste \& Romberg gravimeters (Fig. 1(b)). From now on, we restrict our attention to the one-year period between March 2011 and March 2012; the data in August 2011 indicates significant groundwater disturbance to the observed gravity (Ueki et al., 2011) as discussed in Subsection 2.4.

\subsection{Spatial gravity changes in the year following the 2011 eruption}

The gravity measurements are tied to the absolute gravity data at KVO so that we may determine absolute gravity value at each points. Figure 6(a) shows the gravity change $\Delta g$ in the year following the 2011 eruption.

\section{Modeling the Volcanic Activity}

Horizontal and vertical displacements from February 2011 to February 2012 were reported and analyzed by the Geospatial Information Authority of Japan et al. (2012). They proposed a source model composed of a point inflation/deflation source (the Mogi source) and a rectangular tensile dislocation, representing a deeper magma reservoir and a shallower dike as suggested from the horizontal displacement. This model is consistent with our conceptual model used for interpreting the short-term absolute gravity change in the sense that the shallower dike does work as the valve illustrated in Fig. 4. We thus assume the same configuration for the source model (Fig. 7) and estimate its parameters by performing a simultaneous inversion of our gravity data (Fig. 6(a)) and the observed displacements. Specifically, we minimize the norm

$$
\begin{aligned}
L & =\sum_{j=1}^{n}\left(\frac{g_{j}^{o}-g_{j}^{c}}{\sigma_{j}^{g}}\right)^{2}+\sum_{i=1}^{m}\left(\frac{w_{i}^{o}-w_{i}^{c}}{\sigma^{w}}\right)^{2} \\
& +\sum_{i=1}^{m}\left(\frac{u_{i}^{o}-u_{i}^{c}}{\sigma^{u}}\right)^{2}+\sum_{i=1}^{m}\left(\frac{v_{i}^{o}-v_{i}^{c}}{\sigma^{v}}\right)^{2}
\end{aligned}
$$

where $g_{j}$ represents the gravity change at the $j$-th point and $\left(u_{i}, v_{i}, w_{i}\right)$ eastward, northward and upward displacement components at the $i$-th point, respectively. The superscripts $o$ and $c$ stand for observed and calculated values. The denominators $\sigma_{j}^{g}, \sigma^{u}, \sigma^{v}$ and $\sigma^{w}$ in Eq. (11) are observational errors for the gravity and displacement data. We adopt $\sigma_{j}^{g}=3 \mu \mathrm{gal}$ and $25 \mu \mathrm{gal}$ for the absolute and relative gravity measurements, respectively. The larger error for the relative gravity arises from unusually strong ground vibrations during our measurements in March 2011 excited by numerous aftershocks of the 2011 Tohoku earthquake. Observational errors of the displacements are taken to be $\sigma^{u}=\sigma^{v}=2 \mathrm{~mm}$ and $\sigma^{w}=5 \mathrm{~mm}$.

Analytical expressions describing displacements and gravity changes for a homogeneous semi-infinite medium

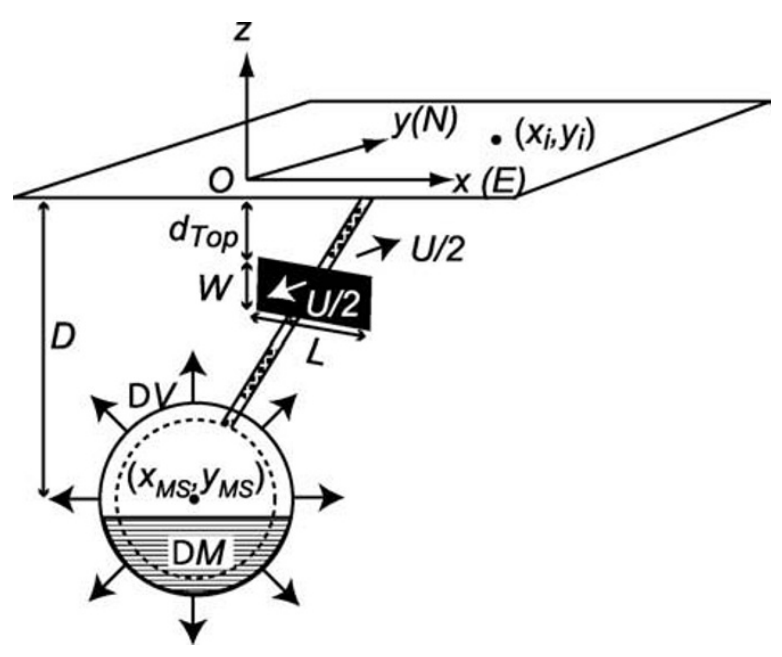

Fig. 7. Source model for interpreting gravity changes (March 2011-March 2012) and displacements (February 2011-February 2012). This model is consistent with the schematic model illustrated in Fig. 4. The conduit is presumed to be partially open to the free space so that the mass change $\Delta M$ is not constrained by the volume change $\Delta V$. 

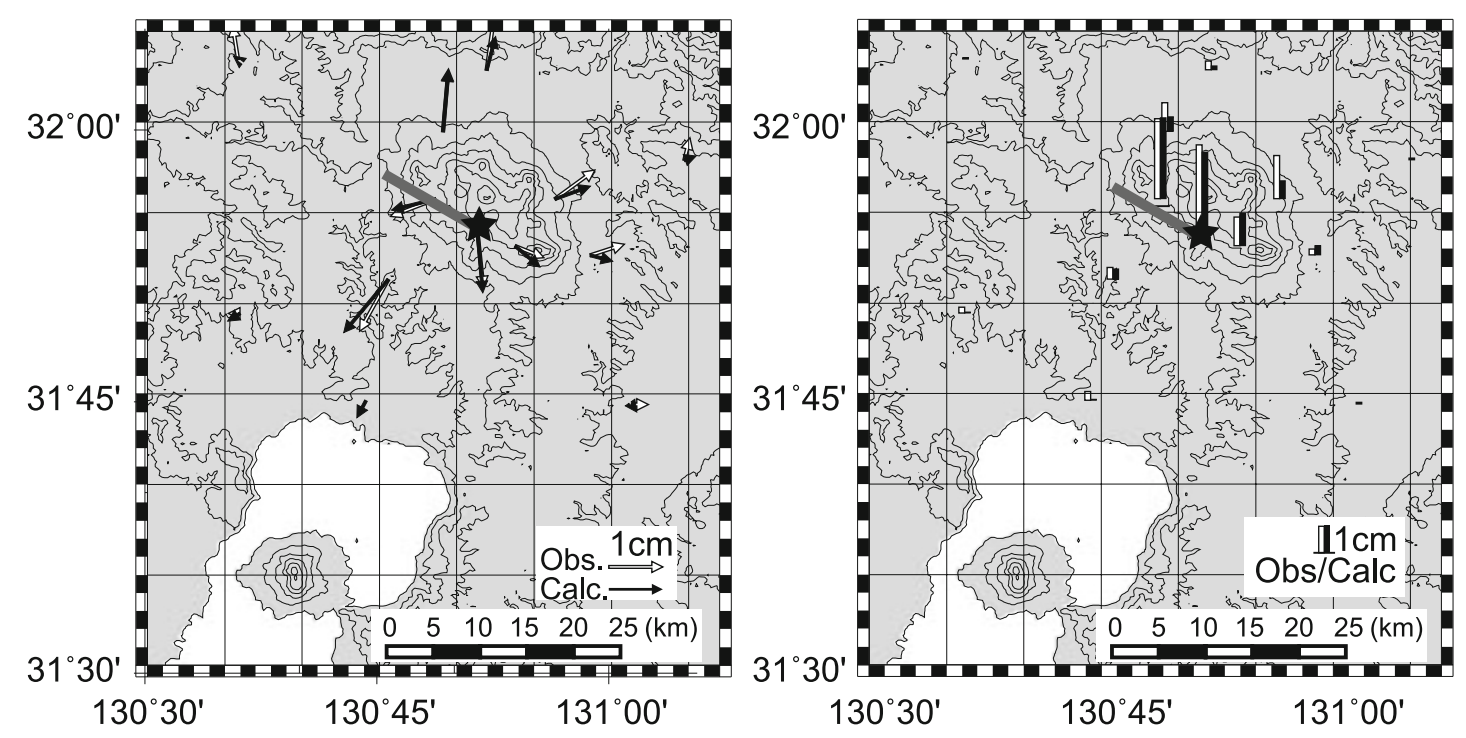

Fig. 8. Displacements on the ground between February 2011 and February 2012. Horizontal and vertical components are shown to the left and right, respectively. "Obs"and "Calc" denote observed displacements after the Geospatial Information Authority of Japan et al. (2012) and those calculated for the model given by Fig. 7 and Table 4, respectively. The star denotes an inflation/deflation source at $9 \mathrm{~km}$ depth while the shaded rectangle represents a shallower dike.

are employed for $\left(u_{i}^{c}, v_{i}^{c}, w_{i}^{c}\right)$ and $g_{i}^{c}$ as

$$
\begin{aligned}
\left(u_{i}^{c}, v_{i}^{c}, w_{i}^{c}\right) & \equiv\left(u^{M}\left(x_{i}, y_{i}\right), v^{M}\left(x_{i}, y_{i}\right), w^{M}\left(x_{i}, y_{i}\right)\right) \\
& +\left(u^{T}\left(x_{i}, y_{i}\right), v^{T}\left(x_{i}, y_{i}\right), w^{T}\left(x_{i}, y_{i}\right)\right) \\
g_{i}^{c} & \equiv g^{M}\left(x_{i}, y_{i}\right)+g^{T}\left(x_{i}, y_{i}\right) \\
& +\Delta g^{\text {mass }}\left(x_{i}, y_{i}\right)
\end{aligned}
$$

where $x_{i}$ and $y_{i}$ are Cartesian coordinates of the $i$-th point in the horizontal plane (Fig. 7). The terms $u^{M}, v^{M}, w^{M}$ and $g^{M}$ denote contributions from the Mogi source at $\left(x_{M S}, y_{M S},-D\right)$ given by

$$
\begin{aligned}
u^{M}(x, y) & =K \cdot \frac{X}{\left(X^{2}+Y^{2}+D^{2}\right)^{3 / 2}}, \\
v^{M}(x, y) & =K \cdot \frac{Y}{\left(X^{2}+Y^{2}+D^{2}\right)^{3 / 2}}, \\
w^{M}(x, y) & =K \cdot \frac{D}{\left(X^{2}+Y^{2}+D^{2}\right)^{3 / 2}}, \\
g^{M}(x, y) & =-\beta w^{M}(x, y), \\
(X, Y) & \equiv\left(x-x_{M S}, y-y_{M S}\right), \\
K & =\frac{(1-v)}{\pi} \cdot \Delta V,
\end{aligned}
$$

where $\nu, \beta$ and $\Delta V$ are Poisson's ratio $(=1 / 4)$, the freeair gravity gradient, and the volume change, respectively (Mogi, 1958; Hagiwara, 1977; Segall, 2010). The terms $u^{T}, v^{T}, w^{T}$ and $g^{T}$ in Eqs. (12)-(13) denote contributions from dike intrusion represented by a tensile dislocation $U$ on a vertical rectangle (Fig. 7). They are given by Okada (1985) and Okubo (1992, 2005). The last term in Eq. (13) is the Newtonian attraction of mass $\Delta M$ coming from the deep interior to the magma chamber given by Eq. (2).

The optimum parameters minimizing the norm $L$ are listed in Table 4 and the gravity changes and displacements corresponding to the optimum model are shown in Figs. 6 and 8 . Although the displacements are fairly well accounted
Table 4. Source parameters for the model illustrated in Fig. 7 derived from inversion of gravity change (March 2011-March 2012) and displacement data (February 2011-February 2012).

\begin{tabular}{lc}
\hline Parameter & Value \\
\hline & (Inflation source) \\
Location & $\mathrm{E} 130.86^{\circ}, \mathrm{N} 31.91^{\circ}$ \\
Volume change & $\Delta V=6 \times 10^{6} \mathrm{~m}^{3}$ \\
Depth & $D=9.0 \mathrm{~km}$ \\
Mass change & $\Delta M=1.25 \times 10^{11} \mathrm{~kg}$ \\
& (Tensile dislocation on a rectangle) \\
& E130.86, $\mathrm{N} 31.91^{\circ}$ \\
& $L=10 \mathrm{~km}$ \\
Location (SE corner) & $W=0.5 \mathrm{~km}$ \\
Length & $d_{\text {Top }}=0.5 \mathrm{~km}$ \\
Width & $90^{\circ}$ (fixed) \\
Depth to the top edge & $300^{\circ}$ \\
Dip angle & $U=0.5 \mathrm{~m}$ \\
Strike angle from north & \\
Tensile opening &
\end{tabular}

for, the observed and computed gravity changes agree rather poorly, implying that the simple comparison of gravity data sets taken in the same season is still affected by disturbances of non-volcanic origin. For example, the gradual and/or episodic downhill flow of $2 \times 10^{7}$-ton of tephra erupted in January 2011 (Nakada et al., 2013) is likely to introduce a gravity increase exceeding $10 \mu \mathrm{gal}$ at points $3 \mathrm{~km}$ from the crater of Shinmoe-dake. In addition, year-to-year variations in precipitation at points closer to the volcano summit is expected to be larger than those at the absolute station. These points suggest that the large gravity increases of 30$40 \mu \mathrm{gal}$ in Fig. 6(a) are of non-volcanic origin. They preclude us from constraining the mass change in a reasonable way. In fact, we obtained a geophysically unrealistic value of $\Delta M>10^{11} \mathrm{~kg}$ when no upper bound is imposed on $\Delta M$ while the volumetric change should be of $10^{7} \mathrm{~m}^{3}$ or so. 
The optimum value of the objective function $L$ defined by Eq. (11) is $L=51.1$, which is comparable with the value of $43 \pm \sqrt{(2 \times 43)}$ expected for a variable drawn from a $\chi$ squared distribution with $(n+3 m-p)$ degrees of freedom (Menke, 1989), where $p$ stands for the number of source parameters $(n=15, m=13$ and $p=11$ in our case). The inferred depth to the deep inflation/deflation source is $9 \mathrm{~km}$, a value consistent with Nakao et al. (2011), while the dike intrusion parameters are in reasonable agreement with values obtained by the Geospatial Information Authority of Japan et al. (2012).

A final comment on possible topographic effects on the deformation is appropriate. Segall (2010) showed that when the ratio of the topographic height-to-length scales $H / L$ is less than 0.05 , the perturbation to the vertical displacement for a flat earth is less than $15 \%$ when an inflation source is buried at a depth $5 \mathrm{~km}$. Since $H \approx 1,000 \mathrm{~m}$ (Fig. 1) and $L \approx 20 \mathrm{~km}$ (Fig. 8 ) in our case, we may safely ignore topographic effects.

\section{Conclusions and Discussion}

We carried out absolute gravity measurements at Kirisima Volcano Observatory over 13 months from February 2011, two weeks after the onset of the 2011 Shinmoedake eruption, until March 2012. The data reveal precursory gravity decreases lasting 5-6 hours followed by abrupt gravity increases lasting 1-2 hours during the first 2 months when the Shinmoe-dake volcano was erupting frequently. Most such changes are associated with and preceded eruptions or aborted eruptions inferred from ground tilt changes. Local gravity around Shinmoe-dake volcano exhibited increase of several to several tens $\mu$ gal during the one-year period following the 2011 Shinmoe-dake eruption. We have derived a physical model that provides a quantitative explanation of the long-term local gravity changes and displacements measured with GPS. This model is consistent with a conceptual model of the volcano's magma plumbing system based on the short-term absolute gravity changes observed prior to vulcanian eruptions.

Acknowledgments. We express our sincere thanks to the Japan Meteorological Agency for providing us with ground tilt data at Takachihogawara. Special thanks are given to the Geospatial Information Authority of Japan, the Japan Meteorological Agency and National Research Institute for Earth Science and the Disaster Prevention for allowing us to use the displacement data derived from the GNSS. Drs. J. Oikawa, A. Watanabe and K. Aizawa are acknowledged for their technical support in acquiring the absolute gravity data. The critical comments of anonymous reviewers were helpful in improving this manuscript. This work was supported in part by Grant-in-Aid for Scientific Research (22900001 and 23244092). Some of the figures were prepared using the GMT program (Wessel and Smith, 1998).

\section{References}

Davis, J. C., Statistics and Data Analysis in Geology, 646 pp., John Wiley \& Sons, New York, 1986.

Geospatial Information Authority of Japan, National Research Institute of Earth Science and Disaster Prevention, and Japan Meteorological Agency, Report to the Coordinating Committee for Prediction of Volcanic Eruptions, February 2012.
Hagiwara, Y., The Mogi model as a possible cause of the crustal uplift in the eastern part of Izu Peninsula and the related gravity change, Bull. Earthq. Res. Inst., Tokyo Univ., 52, 301-309, 1977.

Imakiire, T. and A. Oowaki, Source model of Kirishima volcano based on GPS integrated analysis in volcanic region, J. Geospatial Information Authority of Japan, 121, 183-188, 2011 (in Japanese with English abstract).

Imanishi, Y., K. Kokubo, and H. Tatehata, Effect of underground water on gravity observation at Matsushiro, Japan, J. Geodyn., 41, 221-226, 2006.

Japan Meteorological Agency, Fukuoka District Meteorological Observatory, Kagoshima Local Meteorological Observatory, and J. Funasaki, Eruption of Shinmoedake volcano, Kirishimayama after Jan. 2011, Abstract 2011 Fall Meeting of the Volcanological Society of Japan, 9, 2011 (in Japanese).

Kato, K. and H. Yamasato, The 2011 eruptive activity of Shinmoedake volcano, Kirishimayama, Kyushu, Japan-Overview of activity and Volcanic Alert Level of the Japan Meteorological Agency-, Earth Planets Space, 65, this issue, 489-504, doi:10.5047/eps.2013.05.009, 2013.

Kazama, T. and S. Okubo, Hydrological modeling of groundwater disturbances to observed gravity: Theory and application to Asama volcano, central Japan, J. Geophys. Res., 114, B08402, doi:10.1029/2009JB006391, 2009.

Menke, W., Geophysical Data Analysis; Discrete Inverser Theory, 289 pp., Academic Press, San Diego, 1989.

Mogi, K., Relations between the eruptions of various volcanoes and deformations of the ground surfaces around them, Bull. Earthq. Res. Inst., Tokyo Univ., 36, 99-134, 1958.

Nakada, S., M. Nagai, T. Kaneko, Y. Suzuki, and F. Maeno, The outline of the 2011 eruption at Shinmoe-dake (Kirishima), Japan, Earth Planets Space, 65, this issue, 475-488, doi:10.5047/eps.2013.03.016, 2013.

Nakao, S., Y. Morita, K. Goto, H. Yakiwara, S. Hirano, J. Oikawa, H. Ueda, T. Kozono, Y. Hirata, H. Takahashi, M. Ichiyanagi, Y. Ohta, T. Matsushima, and M. Iguchi, Crustal deformation before and after eruption on Jan. 26, 2011 in Kirishima Shinmoedake, Japan, Abstract 2011 Fall Meeting of the Volcanological Society of Japan, 27, 2011 (in Japanese).

Niebauer, T. M., G. S. Sasagawa, J. E. Faller, R. Hilt, and F. Klopping, A new generation of absolute gravimeters, Metrologia, 32, 159-180, 1995.

Okada, Y., Surface deformation due to shear and tensile faults in a halfspace, Bull. Seismol. Soc. Am., 75, 1135-1154, 1985.

Okubo, S., Potential and gravity changes due to shear and tensile faults in a half-space, J. Geophys. Res., 97, 7137-7144, 1992.

Okubo, S., Gravity changes associated with volcanism-Observation, theory, and analysis, Bull. Volcanol. Soc. Jpn., 50, S49-S58, 2005 (in Japanese with English Abstract).

Okubo, S., S. Yoshida, T. Sato, Y. Tamura, and Y. Imanishi, Verifying the precision of a new generation absolute gravimeter FG5-Comparison with superconducting gravimeters and detection of oceanic loading tide, Geophys. Res. Lett., 24, 489-492, doi:10.1029/97GL00217, 1997.

Segall, P., Earthquake and Volcano Deformation, 432 pp., Princeton University Press, Princeton, 2010.

Suzuki, Y., M. Nagai, F. Maeno, A. Yasuda, N. Hokanishi, T. Shimano, M. Ichihara, T. Kaneko, and S. Nakada, Precursory activity and evolution of the 2011 eruption of Shinmoe-dake in Kirishima volcanoinsights from ash samples, Earth Planets Space, 65, this issue, 591-607, doi:10.5047/eps.2013.02.004, 2013a.

Suzuki, Y., A. Yasuda, N. Hokanishi, T. Kaneko, S. Nakada, and T. Fujii, Syneruptive deep magma transfer and shallow magma remobilization during the 2011 eruption of Shinmoe-dake, Japan-Constraints from melt inclusions and phase equilibria experiments-, J. Volcanol. Geotherm. Res., 257, 184-204, 2013 b.

Torge, W., Gravimetry, 465 pp., de Gruyter, Berlin, 1989.

Ueki, S., S. Okubo, H. Oshima, T. Maekawa, and Y. Tanaka, Precise microgravity measurements at Kirishima volcano, Abstract 2011 Fall Meeting of the Volcanological Society of Japan, p. 26, 2011 (in Japanese).

Wessel, P. and W. H. F. Smith, New, improved version of Generic Mapping Tools released, Eos Trans. AGU, 79(47), 579, 1998.

S. Okubo (e-mail: okubo@eri.u-tokyo.ac.jp), Y. Tanaka, S. Ueki, H. Oshima, T. Maekawa, and Y. Imanishi 